\title{
FISCAL YEAR 1973 SUMMARY REPORT FOR THE USAEC DIVISION OF APPLIED TECHNOLOGY - ENVIRONMENTAL ANALYSIS
}

July 5,1973

Prepared for U.S. Atomic Energy Commission under contract No. W-7405-Eng-48
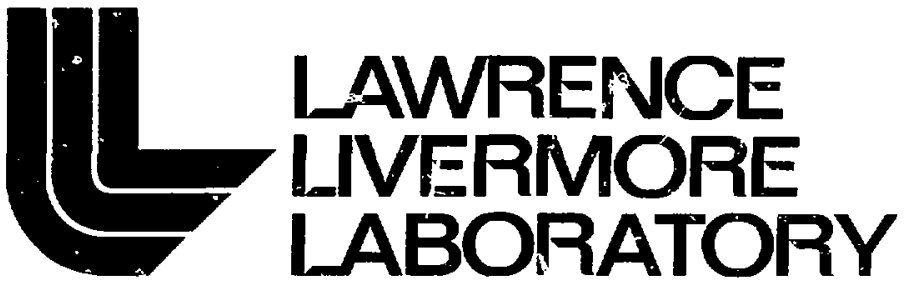

University of California/Livermore 


\section{Notict:}

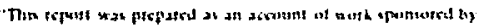

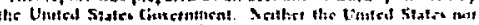

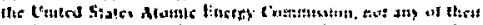

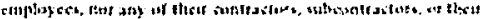

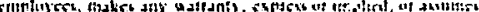

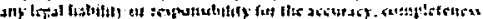

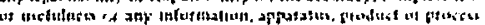

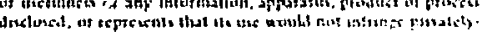
onitest ethlils.

Printed in the United States of America Available from

National Technical Information Service

U.S. Department of Commerce 5285 Port Royal Road Springfield, Virginia 22151

Price: Printed Copy $\$$

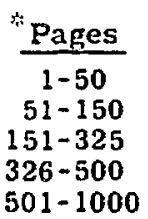

NTIS

Selling Price

$\$ 4.00$

$\$ 5.45$

$\$ 7.60$

$\$ 10.60$

$\$ 13.60$ 
Tii)-4500, $20-41$

IJealth and Safety

\section{逭 \\ LAWRENCE LNESMMPFE I.ABOAATOAY

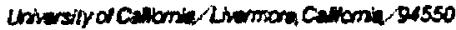

\section{UCRL-51+22 \\ FISCAL YEAR Y973 SUMMARY \\ REPORT FOR THE USAEC DIVISION OF \\ APPLIED TECHNOLOGY - ENVIRONMENTAL ANALYSIS}

Mis. date: July 5, 1373

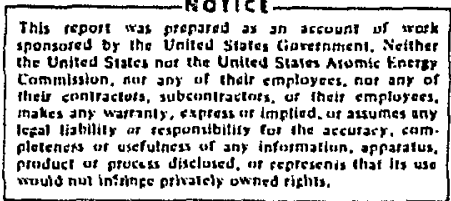




\section{Foreword}

The data contained herein is a compilation of environmental analysis and feasibility studies conducted for the 'SAEC's Division of Applied Technology. Readers who are interested in more detail regarding any item may contact the authors of the reports who are listed in the Contents. 


\section{Contents}

\section{Reports}

Comparison of the Absolute Borrmann Transmission of Ge and CdTe

Detector Grade Crystals (W. L. Pickles and J. H. Elliott) . . 1

Thermoluminescence of Asbestos (T. M. Distler and 1'. E. Barry) . 5

Analysis of Marine Sediment (J. L. Cate, Jr. and W. L. Pickles) . 7

Using the Thermoluminescence of Beach Sand as a Tracer (A. J. Toy,

C. W. Sundbeck, and P. E. Barry) . . . . . . . . 10

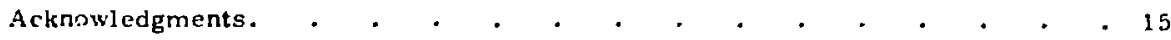

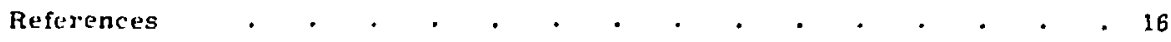

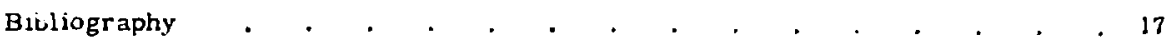

Edited by B. N. Odell 


\section{REPORTS}

\section{Comparison of the Absolute Borrmann Transmission of Ge and CdTe Detector Grade Crystals}

\section{Intruduction}

We conducted a study to compare the iransmission qualities of detector grade Ge with samples of detector grade CdTe and to determine if the CdTe crystals were sufficiently ordered to allow any Borrmann transmission. If the CdTe crystals exhibit strong Borrmann fifects, the implication is that the crystal order is at least as gcod as that of detector grade Ge. (This should be interesting to anyone trying to build radiation detectors with CdTe.)

\section{Crystal Materials}

The Ge crystal used in this study was produced prior to 1966 and, although previously used in other experiments as an $x$-ray band pass filter, its absolute transmission has not been measured. The crystal was 0.0365 in. thick and its etched faces were eit parallel to the (111) plane. The wafer edges had been cut so visual identification of the crystal axes was not pussible. The crystal axes locations when looking on the (111) plane were located using Laue patterns. The CaTe crystal used was provided by the Environmental Analysis bianch of the AFC Division of Technology.

\section{Experimental Approach}

The hardware used in the study was designed and constructed to align a developmental $x$-ray tube with a high resolution silicon semiconductor photon spectrometer and, in addition, to hold the collimators and the rrystal alignment tolder (goniometer). Figure 1 shows all components of the experiment while Fig. 2 shows the

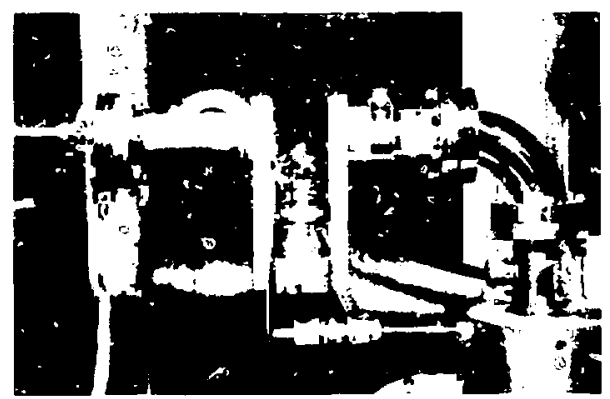

Fig. 1. Experimental apparatus. (Left to right: $X$-ray tube, alignment hardware, and detector.)

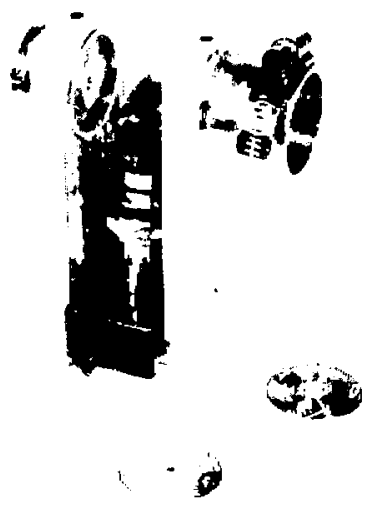

Fig. 2. Alignnient hardware. 
hardwa. Figure 3 shows the goniometer and crystal alune. Note the flexible shaft shown attached to the goniometer in Fig. 1. The flexible shaft is attached to a servomotor to remotely control crystal angle. Figure 4 pictures the electronics associated with the $x$-ray tube, the detector, and the remote control unit.

The divergence of the beam using the 0.125 in. diam aluminum-lined $(20 \mathrm{mil})$ tungster collimators at \pm 1 in. from the crystal was approximately 6 degrees. After accumulation of the transmitted Borrmann Peak Spectrum (see Fig. 5), the germanium crystal was removed and replaced by copper foils. Holding the beam intensity constant, the intensities of the corresponding Borrmann Peak energy component of the beam transmitted through various thi iknesses of copper foil were measured and the results were plotted as shown on Fig. 6. The straight line extrapolation to zero absorber determined the

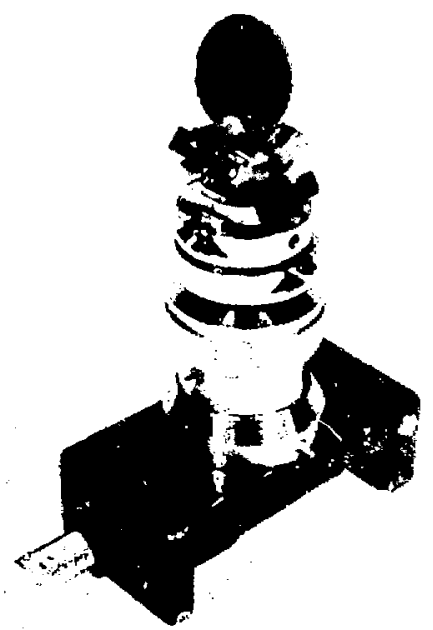

Fig. 3. Goniometer mounted crystal.

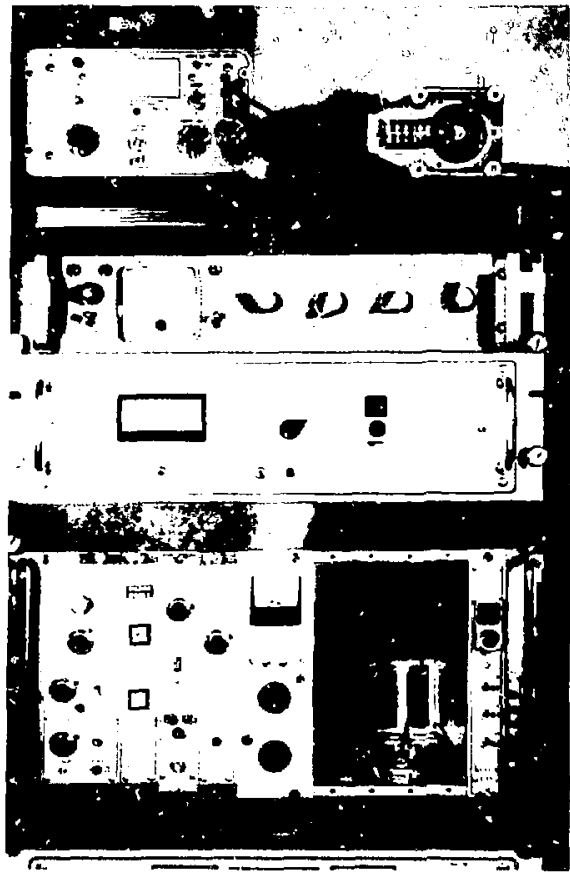

Fig. 4. Electronics.

incident flux. The experiment was repeated substituting the $\mathrm{CdTe}$ for the Ge crystal. The resulting Borrmann transmission, along with the incident spectrum, is shown in Fig. 7. The peak shape is non-gaussian indicating that further investigation should be considered.

Experimental Results

The transmission of $21.5 \mathrm{keV} \mathrm{x}$-rays through the single crystal germanium used in this study was found to be $1.2 \times 10^{-4}$. This is $6 \times 10^{3}$ greater than expected in polycrystalline germanium. The absolute transmission measured through the $\mathrm{CdTe}$ was significantly higher at $3.2 \times 10^{-3}$. (This result should be useful as an evaluation tcol for anyone producing high quality Ge or CdTe crystals.) 


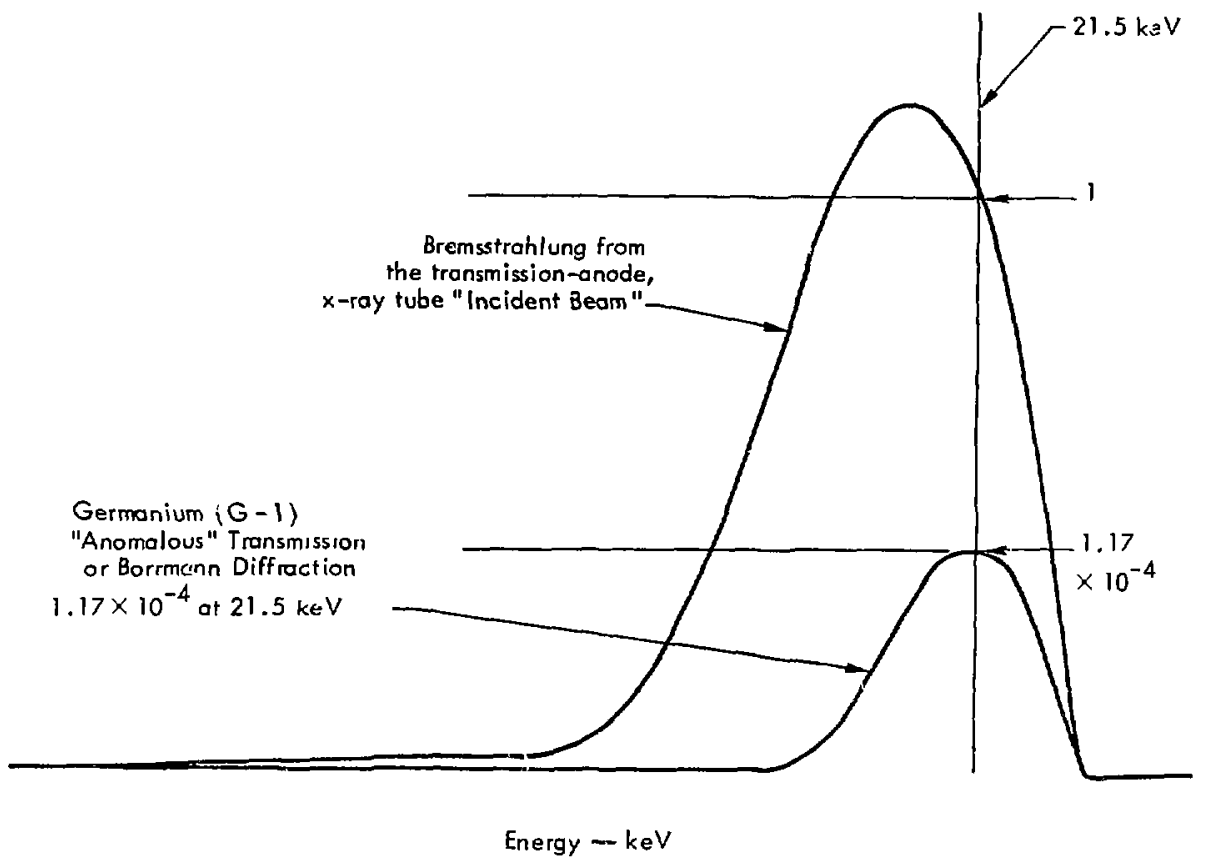

Fig. 5. Comparison of incident and transmitted beams for Ge. 


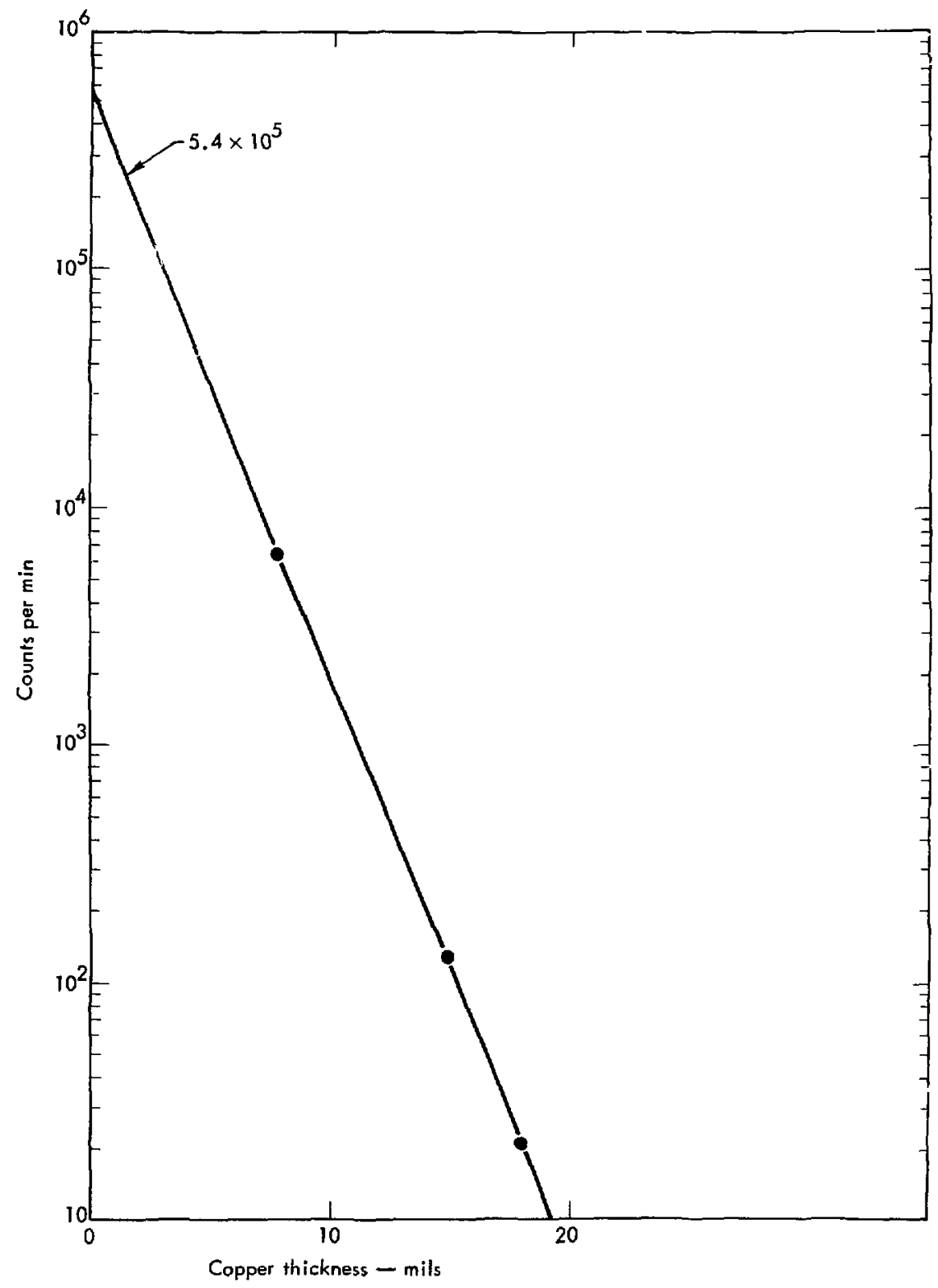

Fig. 6. Variation of intensity with copper adsorber. 


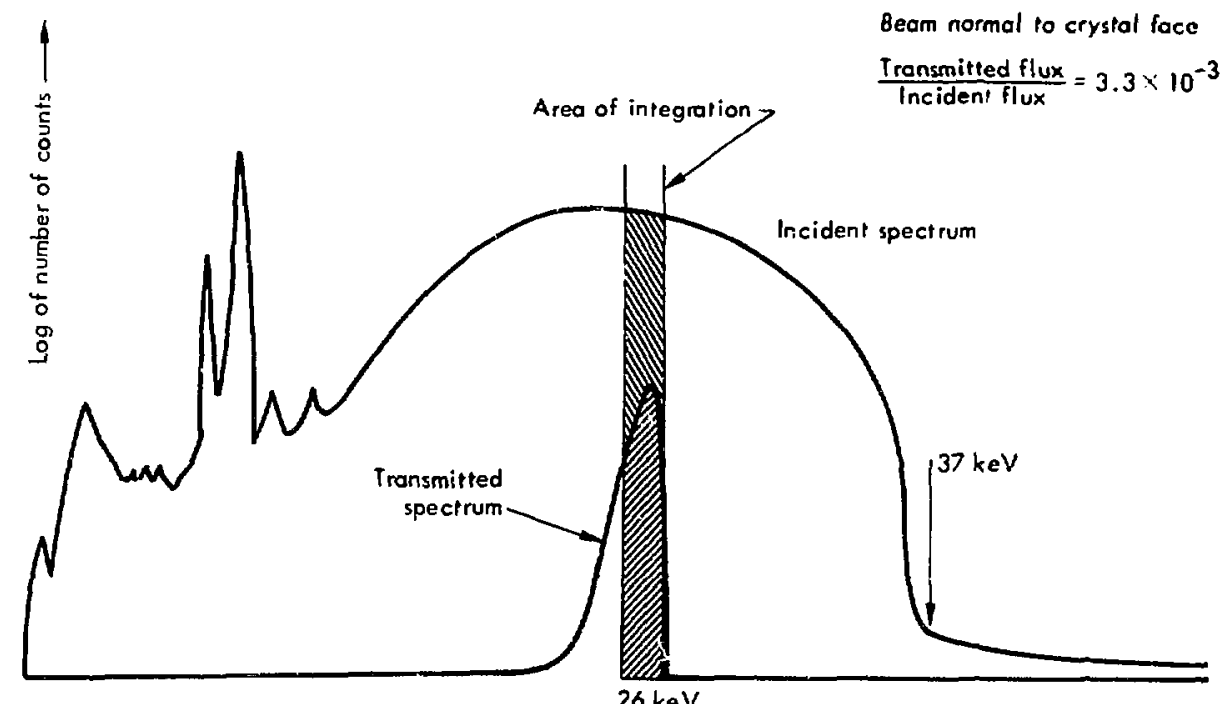

Energy

Fig. 7. Comparison of incident and transmitted beams for CdTe.

\section{Thermoluminescence of Asbestos}

\section{Introduction}

Asbestos concentrations in air are measured by collecting all particles on a filter, preparing the filter for phase contrast microscopy, and then counting the fibers that are longer than $5 \mu \mathrm{m}$ as asbestos. This procedure is tedious, expensive, uncertain, and is not readily amenable to automation due to the great variety of size, form, and contrast of the images.

We began a feasibility study to determine whether thermoluminescence (TL) of irradiated asbestos offers an alternative to the current method. TL is the characteristic luminescence emitted by a stressed material as it relaxes when heat is applied. Ionizing radiation is most often the energy source for inducing $T L$ although mechanical work may produce a similar result.

\section{Objectives}

The initial objectives of this study were to 1) identify characteristic TL parameters that would permit quantitative analysis for asbestos fibers, 2) test for interferences by contaminating materials, and 3) determine a lower limit of detectability. This study was begun using chrysotile, a serpentize asbestos that represents more than $90 \%$ of industrial 
asbestos, If suceessful, the study will be extended to include several raxieties of amphibole asbestos.

\section{Sample Selection}

Samples of chrysotile from several sources were obtained to ensure that the results of experiments would not be due to unique propnrties associated with a particular locality (for example, trace element composition). One type, found at Copperopolis, California, was used to study the effects of pre-irradiation annealing and radiation dose on the $T L$ response.

\section{Experimental Work}

Chrysotile fibers were hand sorted from admixed host rock, dispersed in water, and filtered according to the method ot Badollet and Gantt. ${ }^{1}$ The paper-like filter cake was then cut into 9-mm discs for the TL experiments.

Replicate samples of asbestos discs were annealed at temperatures ranging from room temperature to $425^{\circ} \mathrm{C}$ to remove the luminescence naturally present as well os that mechanically introduced by grinding. Higher temperatures were not used since the available TL reader temperature is limited to $500^{\circ} \mathrm{C}$ and since chrysotile is known to undergo chemical and morphological changes at about $500^{\circ} \mathrm{C}$.

After annealing, samples corresponding to each group of annealing temperatures were exposed to ${ }^{60}$ Co gamma radiation doses of $10^{4} \mathrm{R}, 10^{5} \mathrm{R}$, and $3 \times 10^{6} \mathrm{R}$. Each disc was then read out in a linearly-temperature-programmed TLD reader at $1^{\circ} \mathrm{C} / \mathrm{sec}$ and the glow curve data (luminescence intensity as a function of time) stored in a PDP-11 computer that is interfaced to the reader.
A background glow arre, obtained by re-rcading each dise immediately upon cooling, was subtracted from each intial glow curve. The data were resorded on paper tape and plotted on a Calcomp plotter. Sample.s of serpentine host rock surrounding the fiber ceins and having essentially the same elemental composition werefreed of fibes sand run in the same way.

\section{Observations}

A broab, low-intensity peak centered at about $300^{\circ} \mathrm{C}$ in the TL glow curve was found for all irradiated samples. A precxisting peck in the unannealed material interfered serwowioly with the radiation induced peak. It was found that this cculd be sufficiently reduced by annealing the asbestos discs at 275 ( $\mathrm{C}$ for $1 \mathrm{hr}$ before irradiation. Gamina doses higher than $10^{4} \mathrm{R}$ did not materially improve the $300^{\circ} \mathrm{C}$ glow peak. The highest dose samples showed a brondened peak indicat ing saturation of the $300^{\circ} \mathrm{C}$ peak and the growing in of a higher temperature peak. The scrpentine host rock showed a low peak at $125^{\circ} \mathrm{C}$.

During the course of the work described, a sample that had been read out and left in the reader was unintentionally re-read several days later. It showed an entirely unexpected $T L$ peak in the same region as the radiation induced peak. It was hypothesized that, in the absence of either a radiation field or mechanical excitation, this might have been the result of reabsorption from the air of bound water lost during the TL read out. This was briefly investigated for several unirradiated samples that were annealed, divided into two groups, and then allowed to siand for various times. One group was plased in 
a desiccator over silica gel and the other left open to room air of about $50 \%$ humidity. After $30 \mathrm{hr}$, the samples stored in the desiccator showed no peak regrowth while those left spen to the atmosphere showed a significant peak centered at $300^{\circ} \mathrm{C}$.

\section{Conclusions}

The results thus far indicate that serpentine host rock does not interfere in the TL analysis. Therefore, it is possible to distinguish between the fibrous serpentine, which presents a health hazard, and the innocuous massive sexpentine. However, other data indicate that quartz, a ubiquitous mineral, does have a relatively intense, radiationinduced, glow peak in the $250^{\circ} \mathrm{C}$ to $300^{\circ} \mathrm{C}$ region. ${ }^{2}$ If the peak regrowth behavior is indeed unique to chrysotile, it may offer the required technique for avoiding interferences and eliminate the need for ir radiation. Failing this, spectral discrimination of the luminescence may provide a means of distinguishing between chrysotile and other minerals. Feasibility of the above depends on the TL being intense enough to provide sufficient sensitivity for the detection $i$ i chrysotile at levels of 2 fibers $/ \mathrm{cc}^{3}$ of air. This has not yet been determined.

\section{Analysis of Marine Sediment}

\section{Introduction}

A Coastal Engineering Research Center (CERC) representative informally requested that 15 sediment samples brought to LLL be analyzed using existing $x$-ray fluor escence analysis equipment. Of the 15 samples, 4 were obtained from New York harbor sites and 11 from sites in the New York Bight Dumping Grounds. This report describes the qualitative and relat 'e quantitative analysis performed and concludes with a summary of the fir.dings.

\section{Equipment}

The equipment consisted of a small $x$-ray tube exciter, a scattering chamber/sample changer, a high-resolution $\mathrm{Si}(\mathrm{Li}) \mathrm{x}$-ray detector with associated electronics, and a computer-based, pulse-height analyzer. Figure 8 is a schematic diagram of the system.

\section{Sample Preparation}

The samples obtained were received in the form of dry particulate ( $\varepsilon$ and or silt) and as semi-liquid sludges. Dry material samples in $50 \mathrm{mg}$ batches were placed between two layers of Scotch Magic Mending tape and mounted on 35-mm slide holders (our standard format). For the sludges, approximately $100 \mu \mathrm{l}$ drops were placed on $1 / 2 \mathrm{mil}$ polycarbonate film and dried under heat lamps. When dry, they were sprayed with adhesive, and another layer of film was sealed over the sample. The whole "sandwich" was then mounted in a slide holder.

\section{Analysis}

The samples were exposed to silver $x$-rays (22 and $25 \mathrm{keV}$ ) and their emission spectra collected in the Nuclear Data 4420 Analyzer. Counting times were about $1000 \mathrm{sec}$ (with some considerable variation), 


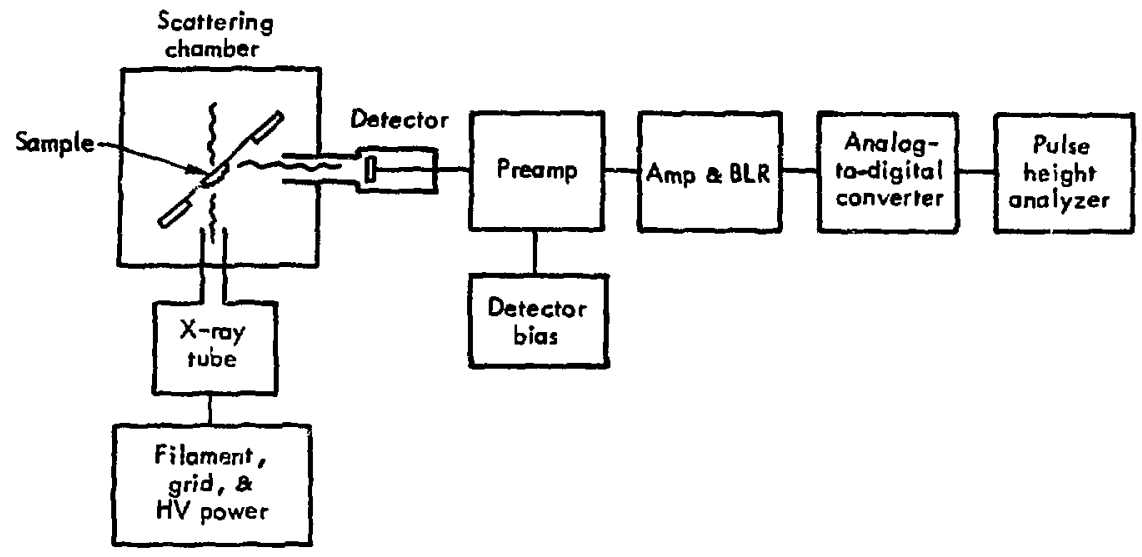

Fig. 8. System block diagram.

Table 1. Relative intensity of interesting $x$-ray peaks.

\begin{tabular}{|c|c|c|c|c|c|c|c|c|c|c|c|c|c|c|c|}
\hline \multirow{2}{*}{$\begin{array}{c}\text { Interva) } \\
\text { No. }\end{array}$} & \multirow{2}{*}{$\begin{array}{c}\text { Sample } \\
\text { element }\end{array}$} & \multicolumn{2}{|c|}{ New York Harbar } & \multicolumn{10}{|c|}{ New York Inght } & \multirow[b]{2}{*}{ I1 } & \multirow[b]{2}{*}{ Mlanix } \\
\hline & & I & 2 & 1 & 2 & 3 & 4 & 5 & 6 & 7 & A & 9 & 10 & & \\
\hline 1 & $\mathrm{Ca}$ & 750 & 652 & 0 & 11 & & 336 & 0 & 3.030 & 739 & 266 & $3+2$ & 64 & 2011 & a \\
\hline 2 & $\pi$ & 3,589 & 3,309 & 1.965 & 3, & & 1,438 & 1,012 & 10.747 & 2.759 & 2,826 & 1.369 & 2.069 & 1.563 & .336 \\
\hline 3 & $\mathrm{Cr}$ & 89 & 570 & 538 & 299 & & 110 & 122 & 19 & 215 & 665 & $13 t$ & 251 & 140 & $\theta$ \\
\hline 4 & $\mathrm{Fe} \mathrm{Kot}$ & 171,247 & 153.152 & 50,632 & $86.43 ?$ & & 25.306 & 13,415 & 368,049 & 158,439 & 169.061 & 119,425 & 107.781 & 5.260 & 1.25 \\
\hline 5 & $\mathrm{Cu}$ & 1,051 & 2.733 & 1,752 & 2,113 & & 1,175 & $2,4+5$ & 7.102 & 2,200 & 2,380 & 1,303 & 1.244 & $\eta_{62}$ & 921 \\
\hline 17 & $2 n$ & 1.330 & 3.938 & $2.26 !$ & $3.29 n$ & & 1,525 & 2.640 & 15.725 & 3.856 & $3,+12$ & 1.580 & $3.4^{45}$ & 1.274 & $75 \%$ \\
\hline B & $\mathrm{Pb} L \mathrm{O}$ & 552 & 1.625 & 182 & 233 & & 0 & 2,212 & 2,734 & $57 z$ & $1.8+5$ & 159 & 2,032 & $71+$ & $2 x^{7}$ \\
\hline 9 & Br & 1.027 & 1,307 & 908 & 510 & & 4s & 823 & 735 & 8s: & 3.658 & 1,029 & 2,310 & $56 \%$ &.$s$ \\
\hline 10 & Po L $\theta$ & +53 & 1.607 & 23 & 451 & & 0 & 1,978 & 1. 196 & B3 & aAO & 628 & 1.51 .7 & $2 B$ & $5+?$ \\
\hline 11 & Ro & 3,892 & 6,520 & 1,341 & 1,171 & & 786 & 1,106 & 6.268 & G. 101 & 2.112 & 4,63 & $1.4+3$ & 1.273 & 0 \\
\hline 12 & $S F$ & 4.730 & 10.590 & 4,066 & 3.582 & & 1.485 & $1,3+1$ & B.217 & +.022 & $\mathrm{i} 3.2 \mathrm{Eq}$ & 2.851 & 2.475 & 5.246 & 0 \\
\hline 14 & $25 \mathrm{Ka}$ & 15,707 & 36,679 & $\{9,822$ & 22.96 B & & 6,817 & 5,513 & 37,325 & 11.084 & $11.5+9$ & 7,620 & $3,+22$ & 71,600 & 0 \\
\hline
\end{tabular}

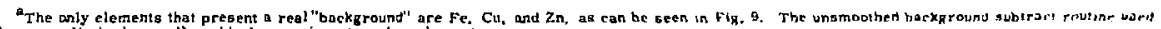
here resolts in the small residusis seen in some olher elements.

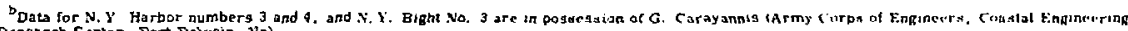
Regea-ch Center, Fort Beivoir, vai).

and the $x$-ray tube was operated at about $150 \mu \mathrm{A}$ beam current (about $1 / 6$ of our normal maximum intensity). Spectra were plotted and analyzed qualitatively, and the net areas of $x$-ray peaks of interest were printed out. Figure 9 and Table 1 show the relative intensity of interesting $x$-ray peaks. Note that this was intended as a qualitative analysis and no effort was made to obtain real quantitative data.
The total effort expended on this job was about 6 man-hr, or 20 min per sample. This figure could be markedly reduced in a routine sampling program by: 1) developing fixturea to hold the slide frames and by pre-cutting the mounting film, 2) reducing counting time to $1-2 \mathrm{~min}$ by running the $x$-ray tube at full power, and 3) using special software to automate data reduction. It is felt that a figure of about 3-5 min per 


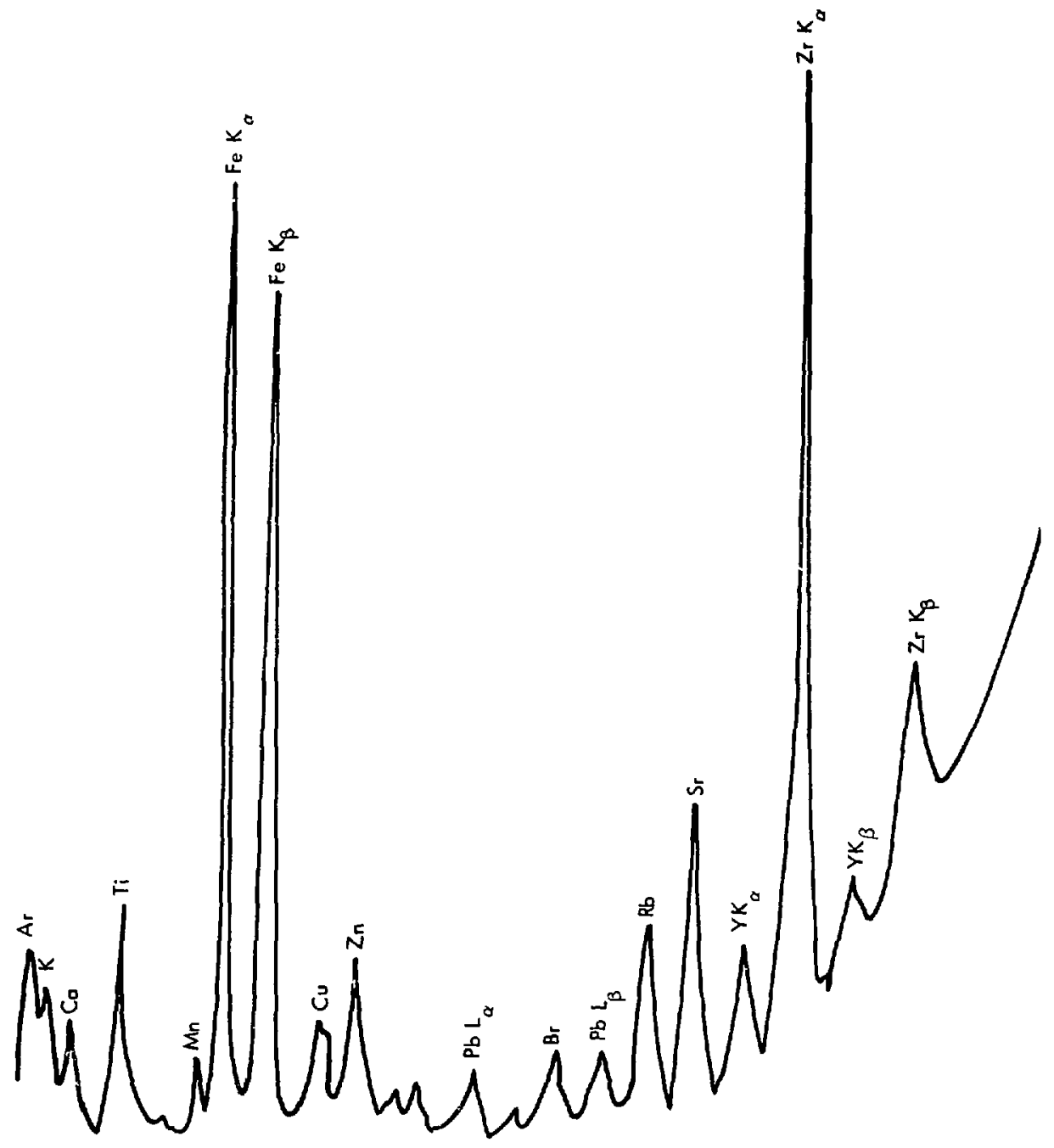

Flourescence

Fig. 9. X-ray fluorescence spectrum from typical New York Harbor sediment sample. 
sample will be realistically approachable.

Quantitative analysis, to an accuracy of $+15^{n \prime}$ and with sensitivitios around the I ppm level ror most elements of $Z$ - 6 , are not difficult and will be available in the near future.

\section{Using the Thermoluminescence of Beach Sand as A Tracer}

\section{Introduction}

We performed feasibility and parameterization experiments to determine if the thermoluminescence (TL) of sand would permit its use as a tracer to study the bottom movement in harbors and beaches. If leasible, a quantity of sand could be removed from an area, be irradiated, and subsequently be dumped back into the water. Samples might then be taken at various times and locations and be washed, dried, and heat ed to measure characteristic TL. Diffusion and migration patterns might then be determined by comparing the TL of sampled sand and the TL of sand irradiated with the same dose as the original material.

\section{Experimental Parameters}

The scope of the experiments conducted focused on TL measurements as a function of:

- Radiation Dose - Is the basic technique feasible and is there a dose that will produce a maximum TL ?

- Mechanical Agitation - Is the TL of sand affected by handling, wave pounding, or current action?

- Pre-irradiation Heat TreatmentIs there an annealing regime that will improve the TL sensitivity or reproducibiiity?

- Source of Sand - What effect will location have on the variability of TL glow peaks and sensitivity?
- Grain Size - Is the Tl, of sand affected by particle sizc and what effect will particle size have on translocation rates"

\section{Experiments and Observations}

Initial investigations were directed at measuring $T L$ as a function of exposure. Figure 10 shows how TL varies with exposure for two samples collected at Half Moon Bay. Aldhugh they do not show a relative maximum, the response to additional radiation is of the functional form $\mathrm{Y}=\mathrm{KX} \mathrm{X}^{\mathrm{a}}$ when the exponent " $\mathrm{a}$ " is less than 1. This indicates that an increase in exposure will result in less increase in signal than if the response were linear.

The $T L$ effect resulting from mechanical agitation proved to be inconsequential. Figure 11 is a glow peak of unirradiated sand that contains a hump from $250^{\circ}$ to $500^{\circ} \mathrm{C}$. The hump is attributed to mechanically stimulated TL triboluminescence which should not interfere with radiation-inducted $T L$ in the $0^{\circ}$ to $260^{\circ} \mathrm{C}$ region.

Samples of purified laboratory sand were annealed at $100,200,300,400$, and $500^{\circ} \mathrm{C}$ for $1 \mathrm{hr}$. Portions of the sand irom each annealing were $i$ rradiated at several exposures between 300 and $1.3 \times 10^{5} \mathrm{R}$. Figure 12 shows the glow curves for the various annealing temperatures and a 
maximum Tl. sensitivity at an annealing temperature of $200 \mathrm{C}$. The next set of experinents showed that the TL sensitivity for unannealed sand and sand annealed at $200^{\circ} \mathrm{C}$ are approximately equal.

Figure 13 shows the response as a function of exposure for a pre-jeractiation annealing temperature of $200^{\circ} \mathrm{C}$, and an approximately lincer response with bose over 3 orders of magnitude.

Experiments were conducted using sand talien from four Bay Area locations selected to represent three geological regimes. ${ }^{3}$ Table 2 shows the sample locations and geological type. Two samples were taken at eack location, one from above the high water mark and a second from the surf. All were washed in deionized water to remove crystallized salts that might give spurious readings and then frecze-dried. Portions of each of the samples were annealed for $1 \mathrm{hr}$ at

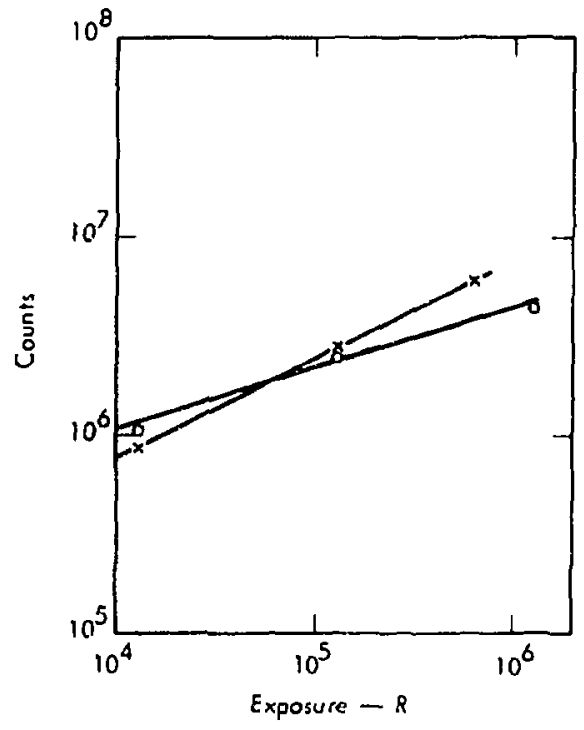

Fig. 10. TL as a function of exposure. $\mathrm{X}=$ Half Moon Bay (in surf) $O=$ Half Moon Bay (above high waterl.

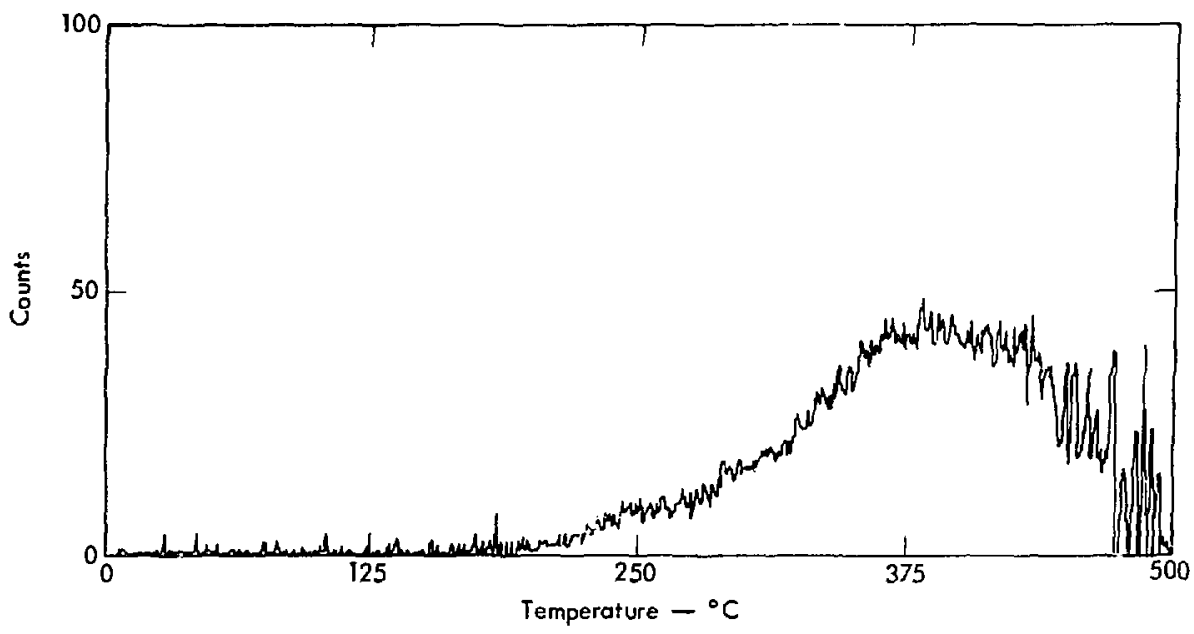

Fig. 11. Glow curve of unannealed and unirradiated sand. 


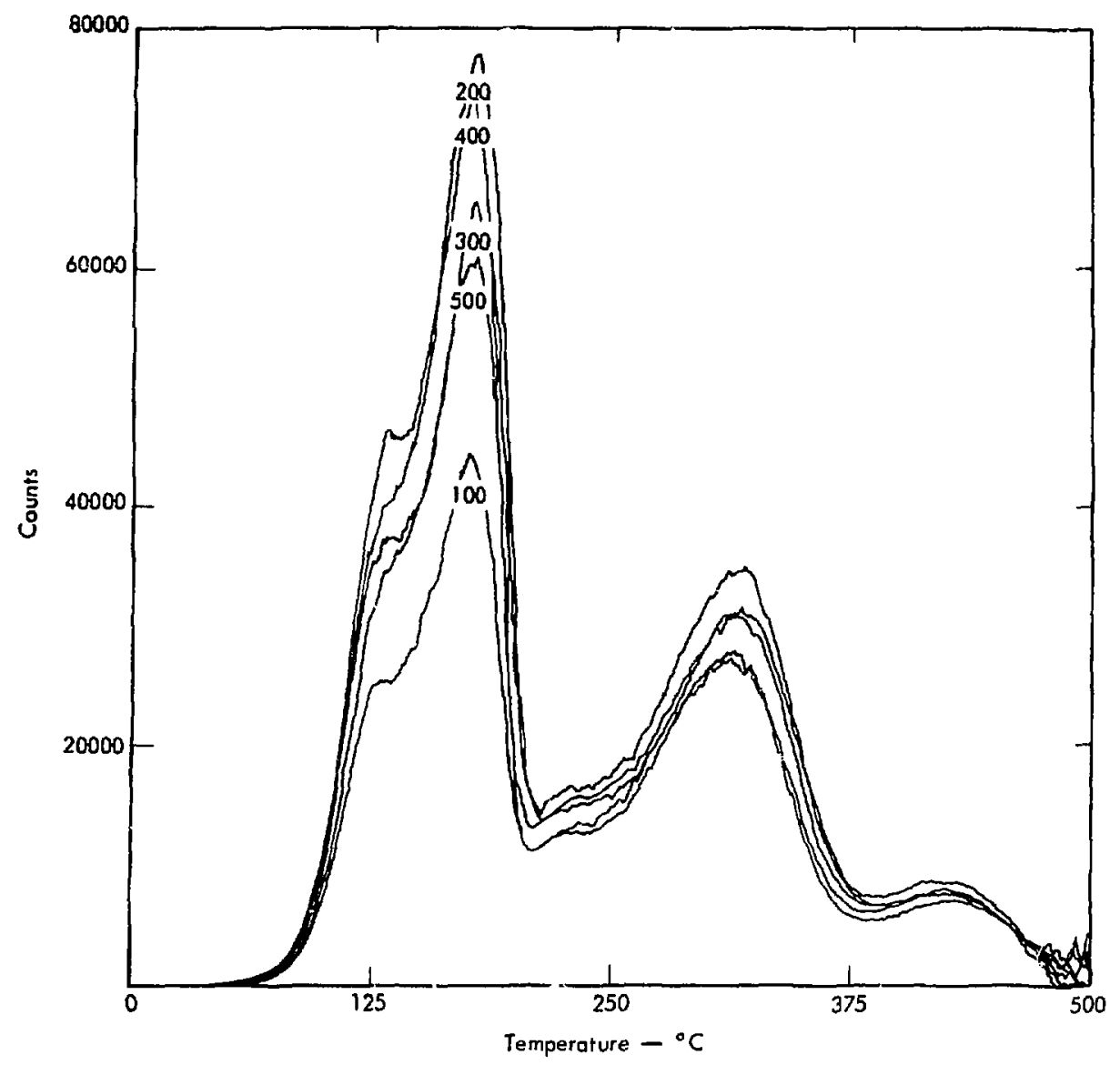

Fig. 12. Glow curves of purified sand at rar sus annealing temperatures.

$200^{\circ} \mathrm{C}$. Both annealed and unannealed samples were exposed to $1.3 \times 10^{4}$, and $6.6 \times 10^{5} \mathrm{R}$ of ${ }^{60} \mathrm{Co}$ gamma rays. Some of the irradiated samples were further separated by particle size (greater or less than 28 mesh) or magnetism.

Figure 14 shows typical glow peaks of the samples taken in the surf at each location. With the exception of the
Sharp's Park sample, the integrated area under the glow peak $\left(60^{\circ}-260^{\circ} \mathrm{C}\right)$ for these samples varies by $15 \%$ from the mcan. This variation compares with a $15 \%$ standard deviation for replicate readings on one sample. The variation of integrated aiea for samples (again excluding the Sharp's Park samples) taken above the high water mark is $44 \%$ of the 


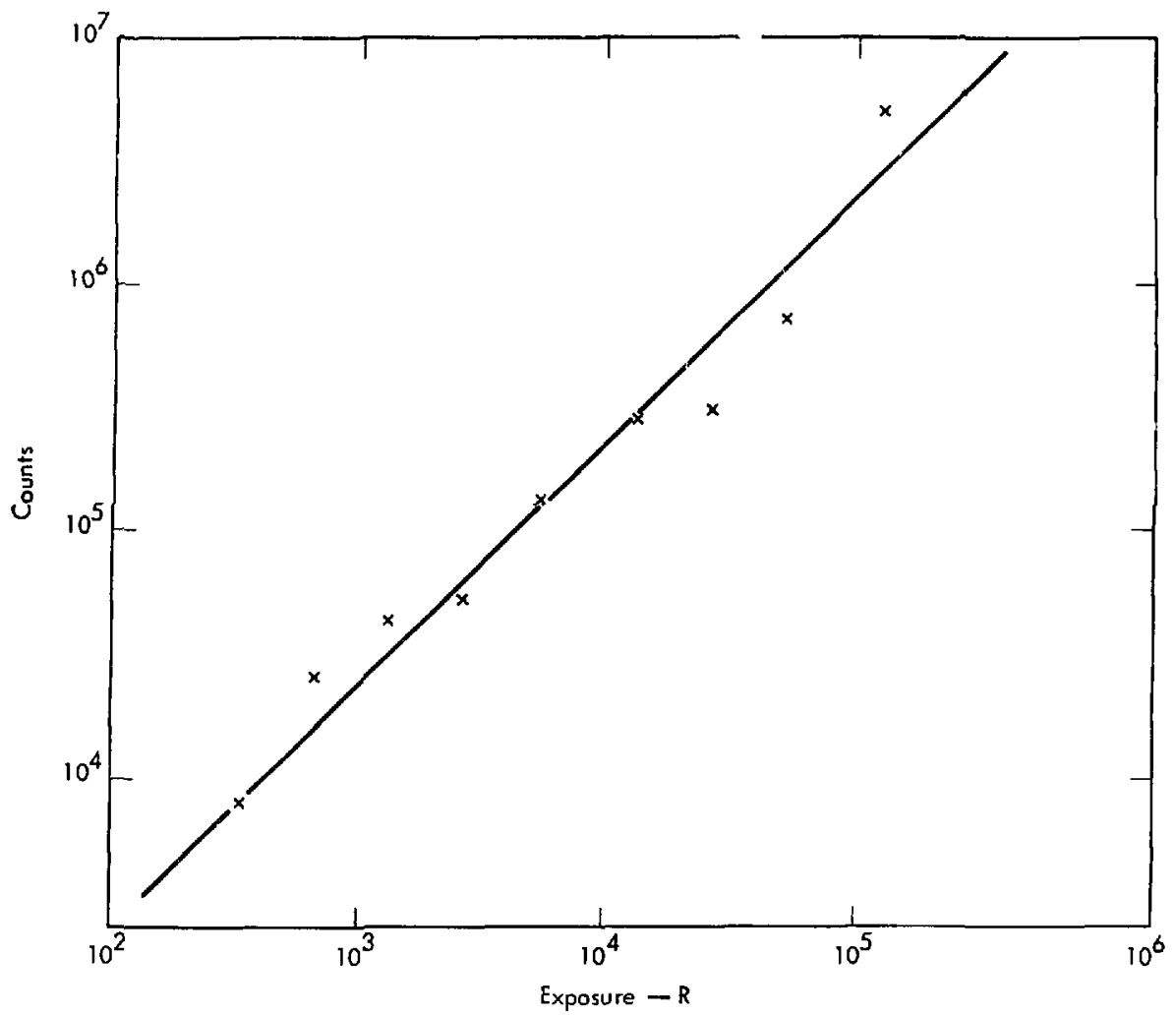

Fig. 13. Integrated $\mathrm{TL}$ output $\left(90^{\circ} \mathrm{C}-210^{\circ} \mathrm{C}\right)$ as a function of exposure, purified sünd and $200^{\circ} \mathrm{C}$ pre-irradiation annealing.

Table 2. Sample locations.

\begin{tabular}{|c|c|}
\hline Location & Geologic regime \\
\hline Stinson Beach & $\begin{array}{l}\text { Late Mesozoic- } \\
\text { Franciscan Formation }\end{array}$ \\
\hline Ocean Beach & $\begin{array}{l}\text { Late Mesozoic - Shelf } \\
\text { and Slope Sedimentary }\end{array}$ \\
\hline Sharp's Park & $\begin{array}{l}\text { Late Mesuzoic- } \\
\text { Franciscan Formation }\end{array}$ \\
\hline Half Moon Bay & $\begin{array}{l}\text { Mesozoic - Intrusive } \\
\text { Granitic }\end{array}$ \\
\hline
\end{tabular}

mean. This is attributed to sand above high water being contaminated with non$T L$ materials since, in each case, the TL was less for samples taken above high water.

The Sharp's Park samples were excluded from the above comparisons because they contain a much higher fraction of black, magnetic, non-TL material which caused the decrease in $\mathrm{TL}$ output. ${ }^{2}$ 


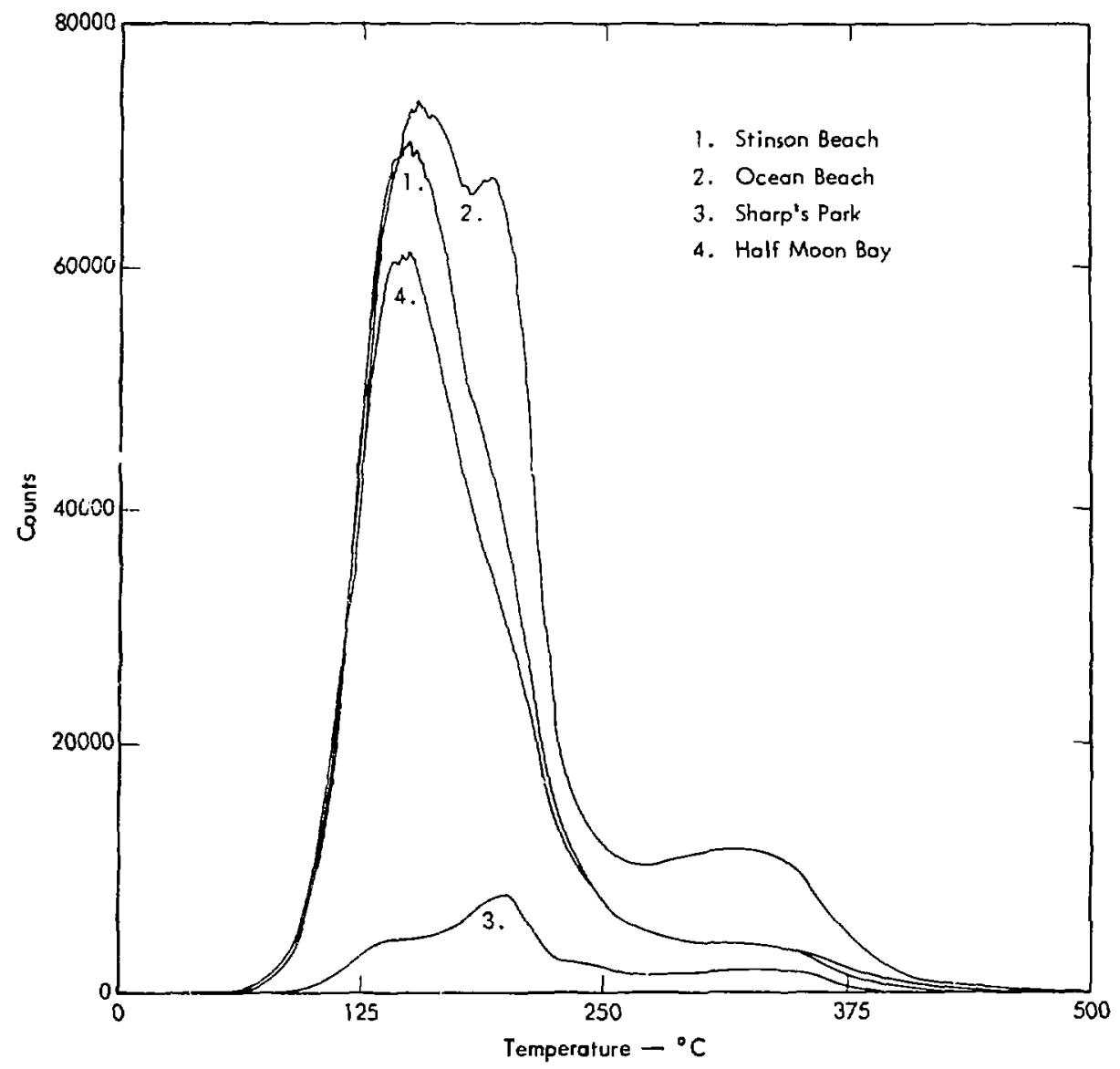

Fig. 14. Glow peaks of sand from various locations.

All of the samples that were siza segregated, except one, showed greater TL sensitivity for smaller grain size. This is attributed to more uniform heating and less $\mathrm{TL}$ absorption within the grain for smaller grains. The sample that did not show increased $\mathrm{TL}$ sensitivity for small grains showed no significant difference in $\mathrm{TL}$ with grain size. This may happen because the large grains in this sample have relatively flat faces, allowing better contact with the TL heater. thus allowing better heat transfer during a heating cycle and consequently a high TL output.

\section{Conclusions}

A TL reader, designed to read sand, may provide better results than the $T L$ reader used in this study. It would be 
required to uniformly heat "large" sand grains to eliminate particle size dependence and have its light collection and filtration optimized for sand samples. Samples exposed to $6 \times 10^{5} \mathrm{R}$ of ${ }^{60} \mathrm{Co}$ gamma rays typically caused the samples to have integrated $T l$, outputs (to $260^{\circ} \mathrm{C}$ ) of several million counts. Inirradiated samples have essentially no signal in the $0^{\circ} \mathrm{C}$ to $260^{\circ} \mathrm{C}$ region. This suggests that it should be possible to approach dilution factors of $10^{6}: 1$ in optimum samples read with optimal readers. Therefore, the $T L$ of sand could be used in experiments to trace the movement of beach and harbor bottoms if the experiment can be done with dilution factors of less than $10^{6}: 1$.

\section{Acknowledgments}

The authors wish to thank Messrs. J. C. Dumpsey and R. L. Butenhoff, AEC HQ(AID), and Drs. G. Pararus-Carayannis, E. E. Fowler, and D. Duane, CERC, for encouraging and supporting this work and to acknowledge their many stimulating ideas and valuable discussions. 


\section{References}

1. M. S. Badollet and W. A. Gantt, Ann, N. Y. Acad, Sci, 132, 451 (1965).

2. Y. Ichikawa and T. Higashimura, "Application of Thermoluminescence of Natural Quartz to Accident Dosimetry," in Proc. Second Intern. Conf. on Luminescence Dosimetry (USAEC Rept. Conf-68090, 1968), pp. 910-915.

3. E. H. Bailey, ed., Geologic Map of California, Compiled by I., S. Geological Survey and California Division of Mines and Geology, Bullet in 190, Geology of Northern California, Platel, (1966). 


\section{Bibliography}

The following represents a library search performed at LLL on the Borrmann effect and its uses.
a. G. Borrmann, Physik Z. 42, 157 (1941).
b. G. Borrmann, "Bie Absorption von Röentgenstrahlen im Fall der Interferenz," Zeitscl:rift für Physik 127, 297-323 (1950).
c. G. Borrmann und W. Gerisch, "Ein Röntgenstrahl-Absorptionsdiagramm von Kalkspat und seine Indizierung," $Z$. für Kristall. 106, 99 (1954).
d. G. Borrmann, "Der kleinste Absorptionskoeffizient interfericrender Röntgen- strahlung," Z. für Kristall. 106, 109 (1954).

e. G. Borrmann, W. Hartwig und H. Irmler, "Schatten von Versetzungslınien im Rontgen-Diagramm," $Z$. Naturforschg. $13 a, 123$ (1958).

f. B. Okkerse, "Anomalous Transmission of $X$-rays in Germanium," Philips Res. Repts. 17, 464-478 (1962).

g. Iames, "The Optical Principles of the Diffraction of X-rays," Vol. II (Cornell University Press (1962).

h. G. L. Clark, (ed.), Encyclopedia of $x$-rays and gamma rays (Reinhold, 1963).

i. B. W. Batterman and H. Cole, "Dynamical Diffraction of X-Rays by Perfect Crystals," Rev. Modern Phys. 36, No. 3, 681 (1964).

j. P. P. Ewald, "Crystal Optics for Visible Light and X-Rays," Rev. Modern Phys. 37, No. 1, $46(1965)$.

k. G. Borrmann and W. Hartwig, "Die Absorption der Röntgenstrahlen im Dreistrahlfall der Interferenz," Zeitschrift für Kristall. 109, 401 (1965).

1. G. Hildebrandt, "Die Absorption von Röntgenstrahlen in Germanium in einem Dreistrahlfall der Interferenz," Phys. Stat. Sol. 15, K131 (1966).

m. P. P. Ewald and Y. Heno, "X-ray Diffraction in the Case of Three Strong Rays," Acta. Cryst. A24, $5(1968)$.

n. P. Penning and D. Polder, "Dynamical Theory for Simultaneous X-ray Diffraction," Philips Res. Repts. 23, 1-24 (1968).

o. T. I. Borodina, A. A. Katznelson, and V. I. Kissin, "Multiple-Beam Borrmann Effect in Perfect Crystals of Germanium and Silicon," Phys. Stat, Sol. (a) $\underline{8}, 105$ $(1970)$.

p. S. Balter, R. Feldman, and B. Post, "Multiple Borrmann Diffraction," Phys. Rev. Letters 27, 6, 307 (1971).

q. R. Feldman and B. Post, "Absorption and Excitation in Multiple Borrmann Diffraction," Phys. Stat. Soì. (a) 12,273 (1972).

r. R. C. Schroeder, On the Anomalous Diffraction of X Rays through Perfect Crystals, Lawrence Livermore Laboratory, Rept, UCRL-50439 Parts I II (1968).

s. R. C. Schroeder, Hupmobile Borrmann Experiment, Lawrence Livermore Laboratory, Rept. UCRL-50512 (1968) (title L, report SRD). 
t. R. C. Schroeder, Procedure Used in Designing the Hupmobile Borrmann Diffraction Experiment, Lawrence Livermore Laboratory, Rept. UCRL-50560 (1968) (title L. report SRD).

u. R. C. Schroeder, Final Report on the Hupmobile Borrmann Experiment, Lawrence Livermore Laboratory, Rept. UCRL-50705 (1969) (title U, report SRD). 